\title{
Predictors of Worsening COVID-19 Illness
}

\author{
Beuy Joob, Ph.D. ${ }^{1}$ (iD and Viroj Wiwanitkit, M.D. ${ }^{2}$
}

${ }^{1}$ Sanitation 1 Academic Center, Bangkok, Thailand, ${ }^{2}$ Dr DY Patil University, Pune, India

We would like to share ideas on the editorial ${ }^{1} . \mathrm{Oh}^{1}$ concluded that "More accurate, simple, and easily applicable tools for predicting worsening oxygenation in coronavirus disease 2019 (COVID-19) for initial risk stratification and medical resource arrangement are needed." Indeed, a prediction of an illness outcome might be useful in management of a patient. In COVID-19, there are limited data or on predictive parameter. The clinical parameters are usually studied on usefulness for prediction of course of disease. However, there are many factors that can determine the outcome. The given therapy might be an important factor. The genetic background is also possible factor determining an outcome. However, there are also non-clinical factors that might be associated with disease progression. Meteorological factors might affect the disease but the environmental factor is hard to control.

Finding for a simple tool for prediction is a good idea. At present, the attempt to develop computational tool to help prediction is also interesting ${ }^{2,3}$. A simple tool should be from basic clinical parameter that requires no complicated process to get the data. The predictive model might be developed but it has to be simplified as much as possible. A good model should base on a non-subjective parameter. Some parameters such as imaging finding might be highly variable among different practitioners. The application of the predictive model based on a local dataset might be appropriate for a specific setting. For example, the predictive model based on chest imaging might be applied in many setting but it might be limited in the setting that occult lung disease, such as tuberculosis, is common. Finally, the prediction might be important but the classic principle to do best for caring of the patient is neces-

Address for correspondence: Beuy Joob, Ph.D.

Sanitation 1 Academic Center, 1 Sanitation 1, Bangkok 103400, Thailand Phone: 66-246582922, Fax: 66-246582922

E-mail: beuyjoob@hotmail.com

Received: Mar. 18, 2021

Revised: Mar. 25, 2021

Accepted: Mar. 31, 2021

Published online: Apr. 2, 2021

(9) It is identical to the Creative Commons Attribution Non-Commercial License (http://creativecommons.org/licenses/by-nc/4.0/). sary. The best care must be given to all patient regardless the prediction result.

\section{Authors' Contributions}

Conceptualization: Joob B, Wiwanitkit V. Writing - original draft preparation: Joob B, Wiwanitkit V. Approval of final manuscript: all authors.

\section{Conflicts of Interest}

No potential conflict of interest relevant to this article was reported.

\section{Funding}

No funding to declare.

\section{References}

1. Oh JY. Predictors of worsening oxygenation in COVID-19. Tuberc Respir Dis 2021 Mar 10 [Epub]. https://doi.org/10.4046/ $\operatorname{trd} 2021.0034$.

2. Shiri I, Sorouri M, Geramifar P, Nazari M, Abdollahi M, Salimi Y, et al. Machine learning-based prognostic modeling using clinical data and quantitative radiomic features from chest CT images in COVID-19 patients. Comput Biol Med 2021;132:104304.

3. Weikert T, Rapaka S, Grbic S, Re T, Chaganti S, Winkel DJ, et al. Prediction of patient management in COVID-19 using deep learning-based fully automated extraction of cardiothoracic CT metrics and laboratory findings. Korean J Radiol 2021;22:e24. 